\title{
América Latina: emergencia de un re-diseño institucional
}

\author{
Diosey Ramón Lugo-Morin
}

PPI / MPPCTII, Caracas, Venezuela. Email: morin@colpos.mx

\begin{abstract}
Resumen: El estudio es una aportación teórica cuyo objetivo es valorar un conjunto de elementos que sustenten la conveniencia de crear un diseño institucional que permita la funcionalidad y permanencia de un modelo de desarrollo de fuerte integración social en América Latina, con énfasis en el caso venezolano. Se construyó un modelo para el diseño de instituciones bajo un marco valorativo neosocialista, con el fin de darles respuestas a la dinámicas de cambios sociales en los territorios venezolanos y America Latina.
\end{abstract}

Venezuela.

Palabras clave: diseño institucional, neosocialismo, integración social,

\section{Latin America: the emergence of an institutional re-design}

\begin{abstract}
The study is a theoretical contribution whose objective is to value the elements that sustain the convenience of creating an institutional design that allows the functionality and permanence of a model of development of strong social integration in Latin America, with emphasis in the Venezuelan case. A model was built for the design of institutions under a neosocialist value framework, with the purpose of giving answers to the dynamics of social changes in the Venezuelan territories and in Latin America.
\end{abstract} zuela.

Key words: institutional design, neosocialism, social integration, Vene-

\section{América Latina: uma re-emergência do desenho institucional}

Resumo: O estudo é uma contribuição teórica tem como objetivo avaliar um conjunto de elementos que sustentam a conveniência de criar um desenho institucional que permite a funcionalidade ea durabilidade de um modelo de desenvolvimento forte de integração social na América Latina, com ênfase no caso da Venezuela . Nós construímos um modelo para o desenho das instituições no âmbito de um quadro de valores neo-socialista, a fim de dar respostas às dinâmicas de mudança social nos territórios da Venezuela e da América Latina.

Palavras-chave: desenho institucional, o neo-socialista, a integração social, na Venezuela. 


\section{Introducción}

El hombre como un ser contradictorio, es solitario y a la vez social; como ser solitario procura proteger su propia existencia y la de los seres de su entorno, satisface sus deseos personales y desarrolla sus capacidades naturales; como ser social intenta ganar el reconocimiento y afectos de los seres humanos que no pertenecen a su entorno inmediato, de esta manera disfruta, comparte y en ocasiones cuando su entorno se lo permite se solidariza. En este contexto, el hombre es un ser complejo cuya génesis transformadora es debida a elementos internos y externos en un equilibrio continuó que le permiten apropiarse y movilizarse en un territorio determinado, en este particular Lugo et al., (2006) han demostrado en estudios recientes la viabilidad de que a partir del conocimiento tácito y codificado los grupos sociales pueden adoptar cambios que conlleven a una transformación interna y externa para favorecer sus estrategias de reproducción ${ }^{1}$. Por otra parte, su naturaleza social lo ha llevado a agruparse y constituir a la sociedad con ciertas normas que le permitan su permanencia en la misma; articulando redes sociales para crear y mantener sus estrategias de reproducción con la finalidad de sostener su condición biológica (ser solitario) y económica (ser social). Estos elementos pueden ser de naturaleza mercantil o no mercantil, esto sustenta suponer que para su materialización se requieren arreglos normados que son regidos por organizaciones o instituciones. La perspectiva analítica Rousseau (1970) destaca algunos elementos que definen la esencia del hombre como ser solitario y como ser social.

Este análisis nos permite ver la relevancia que tiene el hombre en la sociedad y viceversa, en la cual la anarquía interfasica entre los distintos actores ha originado la construcción de organizaciones e instituciones a lo largo del tiempo que regulan sus acciones según las dicotomías de correcto/incorrecto; justo/injusto; bueno/malo; altruista/egoísta. Siguiendo a Echeverri y Moscardi (2005) [...]...la sociedad crea históricamente espacios en los cuales interactúan los intereses individuales, legítimos, de los diferentes individuos, empresas o comunidades. Sin un arreglo público es imposible la coexistencia de los agentes sociales.

En este sentido, el posicionamiento del hombre en el espacio-temporal en una determinada sociedad le obliga a dotarse de un instrumentar ético-moral-religioso que le permita desarrollar sus capacidades naturales no sólo para si mismo, sino para la sociedad donde esta inmerso y externamente norme su permanencia en una formación social. En este contexto, es la sociedad la que provee al hombre de alimento, hogar, herramientas de trabajo, lenguaje, formas de pensamiento y la mayoría del contenido de su pensamiento; estas manifestaciones hacen posible el progreso de la sociedad, esta dinámica ha llevado al ser humano al clímax de su existencia tal como lo señala Bechyn_ (1980), pero a su vez a generado una serie de desequilibrios que amenazan su permanencia. Estos desequilibrios son de origen socioeconómicos y se han concentrado en pocas manos de manera diferenciada a lo que se ha denominado "especies capitales ${ }^{2}$ " representadas en el capital económico, educativo, político, social y ambiental. Pro- 
piciando campos de poder que configuran las dinámicas productivas locales y profundizan la diferenciación regional en términos estructurales, intra y extra locales con otros actores sociales originando patrones de inequidad y exclusión social y en consecuencia asimetrías microterritoriales y extraterritoriales. Este debate lejos de agotarse, se revaloriza desde la perspectiva de la economía institucional donde los actores sociales son un aspecto de relevancia en la construccion de una nueva sociedad, el estudio de Hodgson (2007) es un excelente referente de lo señalado.

La lógica planteada indica la posición estratégica que tienen las organizaciones e instituciones en las transformaciones territoriales impulsadas por el hombre en función de la categorización de los hechos y las acciones. Estas categorizaciones se han movilizado y posicionado en un gran escenario de acción, que no es otro que América Latina, países como Ecuador, Bolivia, Paraguay y Venezuela han iniciado cambios estructurales orientados a crear instituciones abocadas atender las necesidades del hombre como ser social. En este sentido, Venezuela está inventado un nuevo modelo de desarrollo distinto al capitalista con un fuerte componente social.

El presente trabajo plantea como tesis que la recomposición social de América Latina producto de los desequilibrios políticos, ambientales, sociales y económicos a generado el surgimiento de un nuevo modelo de desarrollo basado en una corriente alternativa al capitalismo y al socialismo tradicional y que he denominado "neosocialismo". Su funcionalidad y permanencia dependerá de lo robusto que puedan ser sus instituciones, en este caso es pertinente la construcción de ciertas pautas que permitan su re-diseño.

Para validar este planteamiento, se hace un análisis del panorama teórico de los elementos que sustentan este estudio, abarcando tres ejes analiticos; la primera parte, es una critica al capitalismo latinoamericano en un intento por ubicar un referente analitico al modelo capitalista, el segundo eje plantea el neosocialimos como posibilidad real ante la corriente capitalista, el tercer eje parte, por ubicar la implicaciones de un rediseño institucional apoyado en un caso concreto, el modelo de desarrollo que sustenta Venezuela. Por último, se hace una consideración final y se presentan las conclusiones, así como la bibliografía que respaldo el presente trabajo.

Para describir y comprender los elementos relevantes en el diseño institucional orientado a satisfacer las necesidades del ser social, se elaboró una formulación teórica-metodologica, respecto a los cuales se ha apostado que contribuirá a facilitar su compresión. El trabajo es una aportación con un fuerte componente teórico, que se apoya en un caso concreto de América Latina (Venezuela). El objetivo es valorar un conjunto de elementos que sustenten la conveniencia del re-diseño institucional que permita la funcionalidad y permanencia de un modelo de desarrollo de fuerte integración social en América Latina, con énfasis en el caso venezolano. 


\section{Crítica al capitalismo latinoamericano}

Durante LXII periodo de sesiones de la Asamblea General de la ONU en Septiembre de 2007, el presidente de Brasil, Luiz Ignacio Lula Da Silva criticó fuertemente el modelo de desarrollo actual promovido por el capitalismo y advirtió el declive mundial si no se toman medidas correctivas, algunos de estos elementos se detallan en los trabajos de Jacques (2003), Gutiérrez (2005) y Bourdieu (2006). Estas reflexiones son relevantes porque provienen del gobernante de la primera economía de América Latina, un año después (Septiembre 2008) entra en crisis la economía mundial.

La reciente crisis financiera mundial detonada por la accion colectiva especulativa de los actores sociales del sistema financiero estadounidense pone en evidencia el fin de un modelo de desarrollo impulsado por las motivaciones económicas. En este contexto, se espera una recesion económica global signada por la falta de liquidez y confianza, ante esta situación una de las regiones mejor dotada para enfrentar esta crisis es América Latina. Sin embargo, se estiman impactos en los mercados de las materias primas que eventualmente podrían afectar el equilibrio fiscal de estas economias en términos de ingresos de divisas.

Los rasgos institucionales, los procesos de institucionalizacion y las asimetrías territoriales e inequidades sociales, así como el manejo irresponsable por parte de algunos actores sociales del sistema financiero mundial son variables explicativas; elementos, también, en su dimension espacio-temporal han determinado el declive del capitalismo al menos en América Latina.

Estos elementos han originado un proceso de recomposicion social acelerado en la América Latina contemporanea, palpables por los cambios promovidos en Bolivia, Ecuador, Paraguay y Venezuela en menos de una década (Pereira, 2000; Romero, 2002; Balza, 2002; Banko, 2003; Fernández, 2004; Quijano, 2004; Dupas, 2004; Ayala, 2004; Uharte, 2005; Kliksberg, 2005; Ortiz y Rincón, 2006; Espinoza, 2006; Torrico, 2006; Moreano y Donoso, 2006; Ellner, 2006; Vera, 2006; Rauber, 2006; Monedero, 2007; Vite, 2007, Alayón, 2007) de relevancia porque se han reformulados sus respectivas constituciones políticas (con la excepción de Paraguay), profundizando el carácter social de dichos Estados. Otros países como Brasil, Argentina y México han sido más conservadores, pero sus sociedades, en particular la sociedad rural vive un proceso de empoderamiento cultural (Carretero, 2006; Figueroa, 2006). Estudios realizados por Linck (s/f); Long (1998); Vargas (2003), Rentaría (2003), De Angelis (2003), Sánchez (2004), Meyer (2005) y Leal (2006) coinciden en señalar que la dinámica económica mundial no ha redundado en el fomento de una regulación competitiva pura, sino, al contrario, en procesos de recomposición social y económica en los cuales las interacciones sociales cobran mucha importancia. Por otra parte, señalan acertadamente que estas reconfiguraciones y dinámicas económicas actuales están generando estrategias de respuestas en las sociedades rurales. 
Considerando la lógica de Mészáros (2006) la crisis del capitalismo radica en que el capital es por sobre todas las demás un sistema de control social, ya sea en forma directamente económica o bien en forma política. Este proceso de sometimiento asume la forma de la división de la sociedad en clases sociales englobadoras, pero enfrentadas inconciliablemente entre sí sobre bases objetivas; y bajo el control político. De esta manera que no es nada accidental que el fin de la ascensión histórica del capital en el siglo XX deba coincidir con la crisis del estado moderno en todas sus formas.

El análisis es pertinente porque precisamente en Bolivia, Ecuador, Paraguay y Venezuela imperaron sistemas económicos capitalistas y su declive comenzó cuando dichas naciones no pudieron hacer un control efectivo de su sistema social debido a las asimetrías territoriales e inequidades sociales. Estos aspectos sirvieron de base a la academia para postular un conjunto de teorías que pudieran darle un respiro al sistema capitalista y permitir su continuidad. Por otra parte, el mundo rural ha sido un escenario pertinente de análisis en la construcción de las mayorías de estas teorías.

\section{El modelo capitalista: referencia analítica}

Muchas de las teorias actuales denominadas también "postmodernas" han impulsado debates reflexivos sobre la sociedad actual y los cambios que en ellas están teniendo lugar. El modelo de desarrollo capitalista es uno de los temas sujeto a reflexión y sobre él diversos autores han elaborado distintas concepciones teoricas, entre ellas destacamos: la Nueva Ruralidad, la del Desarrollo Territorial Sustentable, la Neoinstitucional, la Escuela de la Elección Pública y las Fallas del Mercado.

Rubio (2006) destaca que

[...]...estas teorías sin tratar de agotar su contenido, tienen varios rasgos en común. En primer término que no contextualizan los procesos que describen. Sólo describe los aspectos más sobresalientes de la realidad, unos con mayor o menor fortuna, sin cuestionarse su origen y sin ubicar los procesos que visualizan en una etapa determinada. No se sabe si corresponden a una situación de crisis, de transformación o a una nueva etapa del capitalismo. Otro rasgo característico es que no son causales. Los procesos se describen tal como ocurren sin explicar las causas que los originan. Por ello mismo, no se identifica quien dirige las transformaciones y a quiénes y cómo van a beneficiar. En algunas de ellas los agentes sociales aparecen como sujetos incapaces de transformar su realidad, como es el caso de la teoría de la Nueva Ruralidad. Otro rasgo que las caracteriza es que, al no descubrir las contradicciones del capitalismo ni ubicar el proceso de dominio, subordinación y explotación que provocan la desigualdad y la exclusión que enfrentan los agentes sociales, estas teorías justifican el status quo. 
A continuación se detallan cada una de estas teorías:

\section{La nueva ruralidad}

La concepción de una "nueva ruralidad" se inscribe en el proceso de redefinición de las políticas públicas en el conjunto de países de América Latina durante las dos últimas décadas, surge en Europa, durante los años ochenta, después de la crisis del modelo mecánico-químico que trajo consigo un sobrante productivo sin posibilidades de realización, a la vez que un deterioro del medio ambiente. Tal situación llevó al surgimiento de la Nueva Política Agrícola Común, la cual se planteó una racionalización productiva con énfasis ecológico, que llevó a reducir las zonas sembradas, a modificar la orientación de los subsidios y a dar un peso mayor a la conservación del ambiente. Esta políticas significaron procesos de apertura de las economías nacionales y la creación de las uniones comerciales regionales, con el pretexto de la búsqueda de la competitividad en un contexto de crecimiento económico incierto y volátil en el que se aumentaba la vulnerabilidad de la agricultura nacional; en ella se incluyeron también la reducción del gasto público, la disminución de empleo y modificación de condiciones laborales, la privatización a ultranza y con todo ello, una economía muy abierta cuyo equilibrio depende en gran medida de los flujos financieros de origen nacional e internacional (de la Tejera et al., 2006; Rubio, 2006).

El descenso en la rentabilidad de la agricultura minifundista ha obligado a la diversificación de las economías campesinas y al empleo en actividades no agrícolas fuera y dentro del espacio rural, conectándolas cada vez más con los espacios urbanos, particularmente con los mercados de trabajo domésticos y del exterior. Así, se ha configurado una ruralidad asimétrica, con intensas desigualdades económicas, sociales y territoriales, una creciente pobreza, y numerosos conflictos por el acceso a los mercados y a las condiciones básicas de recursos para la producción y la vida comunitaria (de la Tejera et al., 2006).

Esta teoría postula la localización y prosperidad de los espacios rurales, depende de la proximidad de la agroindustria y de los mercados dinámicos. Los espacios rurales localizados en regiones pocos accesibles parecieran que están perdiendo las ventajas de esas interacciones con la ciudad. Debido ha esta dinámica del espacio rural han surgido nuevas funciones de lo rural, la frontera entre lo urbano y lo rural esta desapareciendo creando una organización territorial multipolar con una orientación hacia la integralidad y una recomposición territorial para los actores sociales, estas tendencias obviamente conllevan a nuevas orientaciones de las políticas públicas, así como el diseño y promulgación de leyes orientadas a promover, regular y proteger el desarrollo de este fenómeno.

\section{El desarrollo territorial sustentable}

Esta teoría se encuentra muy hermanada con la Nueva Ruralidad, surge también en Europa en el contexto de la Nueva Política Económica 
como una reacción al modelo de modernización agrícola de la posguerra, que permitió, según este planteamiento, considerables aumentos de la producción y los ingresos de los agricultores, pero al costo de cuantiosas subvenciones que redundaron siempre en el beneficio de una reducida élite de productores y de regiones cada vez más restringidos, mientras que territorios con mayor aptitud agrícola fueron relegados y entraron en crisis económica y demográfica. Señalan que toda región es un sistema abierto y complejo, así como la estructura actual de los procesos de cambio en el territorio. Se considera que el crecimiento económico en un territorio es altamente exógeno, mientras el desarrollo social es fundamentalmente endógeno. Se trata entonces de "endogeneizar" el crecimiento y el desarrollo con base a los potenciales locales y considerando procesos de negociación hacia el entorno (Boissier, 2001; Schejtman y Berdagué, 2003, Rubio, 2006).

El modelo propuesto se fundamenta en varios elementos entre los cuales destacan la definición de territorio y la necesidad de adoptar una visión de país. Esto es, el punto de partida debe ser la definición de una visión de país, cuya aspiración fundamental sea ofrecerle prosperidad a la mayor parte posible de la población rural, meta que solo puede lograrse fomentando la equidad, la competitividad productiva, el manejo sostenible del ambiente, la estabilidad política y la gobernabilidad democrática. Al hablar de prosperidad, el enfoque territorial tiene como referentes indiscutibles, la superación de la pobreza rural y la seguridad alimentaría de la población rural. Así mismo responde a los diferentes eventos realizados en el planeta, orientados a reducir la pobreza, el hambre y la inequidad social, constituyendo una alternativa a los planteamientos convencionales de desarrollo rural.

Hace hincapié en la diversidad social y cultural, el capital social, confianza y redes; el desarrollo de capacidades y capital humano y la posibilidad de instaurar nuevos contratos sociales y culturales para la cohesión social territorial. Con respecto a la participación de los actores sociales en la gestión de los territorios rurales se destaca la importancia de sustituir el enfoque de diferenciación por grupos (p.e., mujeres, jóvenes) por uno de transversalización de actores (p.e., jóvenes agricultores, empresarias rurales). La adopción de un enfoque territorial obedece al establecimiento de una nueva forma de organización social del medio rural: una nueva cultura de producción, consumo y distribución que siente las bases de nuevos tratados sociales y culturales de interacción con el medio, y que otorgue mayores posibilidades de capacitación a la población rural para que estén en condiciones de construir o incorporarse a las oportunidades que promueven el desarrollo. Los actores sociales se conciben como grupos de población con intereses, condiciones y características particulares que los identifican como tales. Aun cuando hay intereses propios e iniciativas que pueden motivar el antagonismo entre actores, éstos también tienen el potencial de cooperar y gestionar acciones conjuntas, con otros actores o con instituciones públicas o privadas, para el bien común de la sociedad rural. Los actores sociales pueden ser individuos, organizaciones, formales e infor- 
males, o instituciones, en tanto que los planes y estrategias de unos coincidan, en determinado momento, con los de los otros.

\section{La neoinstitucional}

Esta teoría surge como reacción al neoliberalismo sin constituir una teoría critica del capitalismo. Siguiendo a Buttel (2005) los enfoques neoinstitucionalistas son en su mayoría de ascendencia neoweberiana y sus fuentes originales provienen de Evans, Du Puis y Vandergeest. Dicha corriente plantea que las reformas económicas y el achicamiento del Estado generaron un vacío institucional, en el cual los productores dejaron de tener interlocutores y se enfrentaron a condiciones de competencia sin posibilidades de éxito.

El neoinstitucionalismo concibe al Estado como una organización dotada de poderes suficientes, para actuar como garante del interés público en un doble sentido: primero, restringiendo la conducta maximizadora y egoísta de los agentes económicos a través del mantenimiento y vigilancia de las instituciones públicas; y segundo, creando nuevas instituciones, en cualquier lugar o circunstancia, donde las instituciones privadas obstruyan o cancelen las posibilidades para obtener las ganancias derivadas de la organización, la cooperación y el intercambio. Esta perspectiva analítica enfatiza la intervención del gobierno como factor regulador del intercambio y correctivo de las fallas del mercado, y no sólo como un agente ético y externo (Ayala, 1996a).

Según Rivas (2003) el neoinstitucionalismo impulsa el cambio institucional partiendo de que este último delinea la forma en que la sociedad evoluciona en el tiempo y es, a la vez, la clave para entender el cambio histórico. Además, dentro del proceso de cambio institucional, según Paul Dimaggio tendríamos o incluiríamos cuatro momentos o etapas a saber: i) la formación institucional; ii) el desarrollo institucional; iii) la desinstitucionalización y iv) la reinstitucionalización.

Desde la perspectiva de análisis de éste estudio, esta teoría ubica unos elementos que son relevantes en un marco de construcción e innovación institucional. Sin embargo, debemos ser cautelosos con su marco valorativo, esta perspectiva surge y se encuadra en una concepción capitalista, no ve más allá de una visión capitalista, esto sin duda crea sesgos analíticos importantes. El diseño institucional acorde a marcos valorativos neosocialistas ofrece retos interesantes que podríamos ubicarlos en dos dimensiones; primeramente, existe un amplio instrumentar teórico que se ha venido enriqueciendo y perfeccionando a través del tiempo y en segundo término, la ausencia de experiencias socialistas genuinas, como un componente esencial para articular un instrumentar metodológico que permita su comprensión, aplicación y replicación en otras regiones. Este último aspecto es relevante, porque precisamente es América Latina la región que esta ofreciendo esta experiencia inédita neosocialista y donde Venezuela, que se perfila como una de las democracias más perfecta del mundo, la 
encabeza o lideriza (Parker, 2006; Chinchón, 2007), porque sencillamente postula que el poder reside en los gobernados y no en los gobernantes.

\section{La escuela de la elección pública}

La teoría de la elección pública es una escuela que se ha desarrollado en la tradición de la economía política, preocupada por tratar de entender los temas relacionados con las elecciones del gobierno en un amplio número de asuntos económicos: el presupuesto público, las políticas de gasto e ingreso, las regulaciones económicas, las tarifas, es decir, aquellas que no ocurren como actos individuales y voluntarios en el mercado, sino como procesos sociales que involucran a los individuos independientemente de su voluntad. Este es un enfoque radicalmente nuevo sobre el papel del Estado en la economía (Tullock) y puede ser entendido como una extensión y aplicación del análisis económico (Buchanan) a la toma de decisiones públicas o colectivas. Aborda temas que la economía o la ciencia política convencionales tradicionalmente habían rechazado (Ayala, 1996b).

Esta teoría se inscribe en el conjunto de las denominadas teorías del Estado “mínimo". Comparte el supuesto de que el mercado es el mecanismo más eficiente para la asignación de recursos; la eficiencia se logra porque la conducta egoísta de los individuos (en la misma dirección que la idea seminal de Adam Smith) conduce a elecciones que maximizan los beneficios individuales y, éstos se extienden a la sociedad en su conjunto. El supuesto de la conducta maximizadora lo extiende al ámbito del análisis de las elecciones públicas, es decir, aquellas que involucran a los individuos organizados en grupos y a sus diversas acciones colectivas. Esta perspectiva, a diferencia de la economía neoclásica, estudia los problemas de asignación de recursos que se originan tanto en el mercado, como en la intervención del Estado en la economía, o en el mercado político (Ayala, 1996b).

\section{Las fallas del mercado}

Los antecedentes de la teoría de las fallas del mercado se remontan a principios del siglo pasado. En efecto, una de las viejas preocupaciones de la economía se refiere a la capacidad del Estado para mejorar el bienestar social, cuestión que llamo la atención de políticos e intelectuales, y no únicamente de los economistas. El interes era estudiar la disyuntiva entre la búsqueda del bienestar social y el logro del beneficio individual. Ello estimuló la búsqueda de teorías y modelos que permitieran analizar estos problemas. M. Olson ha sugerido que la teoría de las fallas del mercado es el descubrimiento más importante de la economía neoclásica y una de las críticas más sólidas para cuestionar la validez de los modelos competitivos. Esta teoría, puso en tela de juicio el principio clásico, de acuerdo al cual, la conducta egoísta de los individuos permitía maximizar los beneficios, no sólo individuales, sino también sociales (Ayala, 1996c). 
La teoría de las fallas del mercado fue una respuesta y critica a la falta de realismo de las teorías basadas en el modelo competitivo. Esta teoría produjo los argumentos más sólidos, desde el punto de vista del análisis positivo y normativo, para la justificación de la intervención estatal. Aunque la teoría de las fallas del mercado ha ganado una amplia aceptación aún se discute si la existencia de las fallas del mercado es, o no, una justificación suficiente para la ampliación de la intervención gubernamental en la economía. Para muchos economistas las fallas del mercado sólo crean las condiciones necesarias, pero no suficientes, para que el Estado intervenga, y piensan que el fortalecimiento de los mecanismos del mercado y la competencia haría redundante la aplicación de intervenciones del gobierno. Por supuesto que en este tema existen distintas posiciones sobre la necesidad de la intervención estatal (Ayala, 1996c; Jeannot, 2000).

El surgimiento de la teoría de las fallas del mercado es un hecho relevante dentro de un marco de análisis postcapitalista, ya que admite que el mercado posee imperfecciones, que pudieran ser corregidas o no por la intervención gubernamental. Los autores señalan que los preceptos que sirven de base a muchas teorías económicas actuales en particular la economía del bienestar, se apoyan en los cimientos de la teoría de las fallas de mercados. Es un paso importante que los propios científicos sociales que apoyan el modelo de desarrollo capitalista admitan que la funcionalidad del mercado por si sólo no mejora la eficiencia económica y puede generar desequilibrios e inequidades a ciertos sectores sociales (por ejemplo, aquellos agentes sociales que hacen vida en el sector rural).

Estas teorías “postmodernas” son como un aliciente de la devastación social que ha generado el capitalismo en el género humano y no humano, surgen para justificar la permanencia del modelo de desarrollo actual (capitalista), a pesar de las múltiples fallas que este posee. Es la manera de cómo la comunidad científica de los países centrales o desarrollados nos dice reiteradamente que no existe un modelo de desarrollo alternativo, y que debemos tratar de sobrevivir con el que tenemos. Sin embargo, en contra posición han surgido científicos sociales que provienen de estos países con un discurso distinto y crítico ${ }^{3}$.

En este sentido, han surgido entre otras, las teorías "Economía Política de la Agricultura” y “Subordinación Desestructurante” la característica fundamental de estas teorías es que son históricas, ya que ubican el análisis en el contexto del desarrollo del capitalismo: la primera como "la crisis de la hegemonía de Estados Unidos” y la segunda como una nueva fase llamada agroexportadora neoliberal. Así mismo, explican las causas de la desigualdad y la exclusión de los campesinos y productores y ubican las contradicciones del capitalismo en esta nueva etapa; delimitan quienes son los beneficiarios del nuevo proceso y asumen una posición crítica ante el capitalismo (Rubio, 2006).

Finalmente, entre las distintas teorias y enfoques han surgidos diversos modelos de análisis, entre ellos destacamos la etnocompetitividad. 
La concepción de etnocompetitividad se inscribe en el proceso de definición ecléctica, este modelo de análisis permite evaluar la construcción social de la subsistencia de las unidades productivas familiares, identificando las prácticas sociales y las interpretaciones culturales desarrolladas por los distintos actores sociales, encabezada por el venezolano Diosey Lugo-Morin, se apoya en la teoría del actor social de Long (1996, 2007) y surge en su fase inicial en Venezuela y posteriormente desarrollada y consolidada en el Colegio de Postgraduados de México como una alternativa metodológica para ubicar las estrategias de reproducción de los grupos familiares en un entorno de permanente cambio y donde el elemento central es el conocimiento local ${ }^{4}$.

La etnocompetitividad ha sido considerada inicialmente como dinámica y flexible, integra procesos relacionales de sistemas organizados. Se define como la capacidad que tiene un grupo social, sustentado en el conocimiento local, para adoptar elementos culturales externos a su dinámica socioeconómica propia; con el fin de mantener su estrategia de reproducción (Lugo, 2006; Lugo et al., 2006). En el ámbito metodológico se aplica a cualquier unidad de producción familiar y opera en función de dos dimensiones, por un lado los elementos internos que afectan la dinámica reproductiva de la unidad y por el otro, los elementos externos que configuran su territorio como así mismo. Estos elementos en su totalidad, de acuerdo a su posición en el territorio y a la dinámica económica que impere, van a impactar de manera específica en la estructura familiar generando respuestas interconectadas. Este enfoque entre otros ha despertado el interes del Sistema Económico Latinoamericano y el Caribe (SELA) en aras de ubicar el modelo de análisis idóneo que permita explicar y disminuir las asimetrías en América Latina y el Caribe.

El debate teórico expuesto en las distintas teorias surge porque a través de éstas se ha pretendido justificar la institucionalizacion de un modelo que acoraza el status quo unos pocos actores sociales. Sin embargo, muchas de ellas caen por la imposibilidad de explicar porque el modelo actual sigue generando patrones de inequidad en los grupos sociales.

\section{Neosocialismo y génesis de un nuevo modelo de sociedad}

La búsqueda de una alternativa al modelo de desarrollo actual no es una idea nueva Rauber (2006) señala que en los años 60 y 70’s en América Latina se debatían fundamentalmente dos concepciones estratégicas para la superación del capitalismo y la construcción de un socialismo: la reformista, que planteaba la revolución por etapas y el camino de reformas como vía para su realización; y la revolucionaria, que centraba todas las fuerzas y capacidades políticas y organizativas en la lucha directa por la conquista del poder político. En ambos casos, se partía de considerar cuatro premisas; i) la abundancia en recursos naturales; ii) que el capitalismo desarrollado sienta las bases para el socialismo; iii) que en el seno del capitalismo es imposible crear las bases de la sociedad socialista y iv) ubicada en el 
ámbito político, afirmaba: que la conciencia se transforma automáticamente a partir de los cambios en la base económica. En el contexto actual, pensar la transformación social hacia el socialismo, en las condiciones de nuestras sociedades en el siglo XXI, supone replantearse las anteriores premisas, cuestionar su vigencia e interrogar abierta y creadoramente a la realidad actual: local, regional, continental, mundial.

Houtart (2001) y Shaikh (2006) han planteado la necesidad de cambiar el modelo de desarrollo actual. El pensamiento teórico y las experiencias prácticas están ahí como prueba, de que es posible un cambio.

\section{Mészáros (2006) plantea}

[...]...la necesidad de construir urgentemente una alternativa radical al modo de reproducción social del capital. El desafío histórico de instituir una alternativa viable al orden establecido también pide una revalorización al fondo del marco estratégico socialista y de las condiciones de su realización, a la luz de los desarrollos y las decepciones del siglo pasado. Necesitamos con urgencia una teoría socialista de la transición, no solo como un antídoto para las absurdas teorizaciones del "fin de la historia" y el concomitante entierro del socialismo. En sus términos propios, y positivos, se necesita una teoría de la transición para reexaminar el marco conceptual de la teoría socialista, que en su origen fue elaborada en relación con el "pequeño rincón del mundo" europeo.

En este sentido, autores como Lebowitz (2006, 2007) y Dieterich $(2003,2007)$ han hecho un esfuerzo por presentar un marco teórico-conceptual de un socialismo de cara al siglo XXI. El primero, destaca la necesidad de redimensionar a la clase obrera, no como abstracción, sino como un actor concreto que cumple una labor en el entramado social, lo que el marxismo unidimensional y el posmarxismo parecen haber olvidado en sus visiones conceptuales. Surge la importancia de establecer los mecanismos para desarrollar las capacidades naturales del hombre para su transformación, que a su vez le permitirán transforma su entorno o territorio. El segundo, intenta establecer los cambios micro y macro socio-estructurales que permitan sustentar un modelo anticapitalista, propone la democracia participativa como la nueva forma de organización social que sustituye a la democracia representativa y diseña los criterios para definir una economía socialista.

El debate teórico apuntala la posiblidad de establecer un modelo económico socialista; en América Latina, Venezuela encabeza las naciones latinoamericanas que cree en un planteamiento real de establecer este modelo. "Tenemos que reinventar el socialismo" declaró Chávez en su discurso de clausura en el Foro Social Mundial del 2005 en Porto Alegre, Brasil. "No puede ser el tipo de socialismo que vimos en la Unión Soviética, sino el que emergerá al desarrollar nuevos sistemas construidos sobre la base de la cooperación, no de la competencia. El capitalismo tiene que 
ser transcendido si queremos en algún momento poner fin a la pobreza de la mayoría de la población mundial. Debemos superar el capitalismo. Pero no podemos recurrir al capitalismo de estado, que seria la misma perversión de la Unión Soviética. Debemos reclamar el socialismo como una tesis, un proyecto y un sendero, pero un nuevo tipo de socialismo, humanista, que sitúe a los humanos y no a las maquinas o al estado a la cabeza de todo".

Desde la perspectiva de análisis del mandatario venezolano, el presente estudio se ha planteado el surgimiento de una nueva corriente que podemos denominar "neosocialismo". El neosocialismo: no es postcapitalista ni representa al socialismo tradicional que caracterizaron a la Unión Soviética, Cuba (Dieterich, 2006) y gran parte de los países de la ex-cortina de hierro que conforman la Europa del Este. Es un sistema que revaloriza al hombre en su integralidad, es decir, como ser solitario y social. Como entidad individual promueve sus capacidades naturales con el fin de que pueda transformar su entorno. Como entidad social intenta articular un mecanismo de control socio-político tanto de influencia interna como externa debido a que es depositario del poder dándole una cualidad anisótropa (restricciones internas y externas que posee un sistema social).

Asimismo, el neosocialismo preserva la propiedad privada y crea otras (un ejemplo concreto es el caso venezolano donde existe la propiedad privada y simultáneamente se plantea la creación de la propiedad mixta, social y comunal), como una estrategia para asegurar su reproducción espacio-temporal. Se destaca que la construcción de un modelo de desarrollo neosocialista desde mi perspectiva de análisis va a operar en dos dimensión. Por un lado, su funcionalidad dentro de un territorio en particular (municipio, estado, región o país) se concebirá por el nivel de felicidad que pueda proporcionar a nivel individual o grupal, es decir, la promoción de las capacidades naturales del individuo puede generar un efecto positivo, la sola consideración de este elemento puede afectar sensiblemente todo un sistema social, pudiendo ser amplificado por el propio sistema. Por el otro, su funcionalidad extraterritorial le permitirá construir instituciones robustas capaces de proyectar derechos de propiedad bien definidos y un sistema de justicia fuerte y estable.

El neosocialismo puede tener efectos económicos positivos y negativos. En el lado, positivo puede ayudar a construir legitimidad y consenso sobre la base del funcionamiento de las normas generales que hacen posible la economía social. Además, es medio para potenciar las capacidades humanas e impulsar las innovaciones. En el lado, negativo puede ser un mecanismo de promoción del caciquismo ${ }^{5}$ o, por medio del cual ciertos grupos sociales capturen el poder y los recursos y servicios provenientes del Estado. Este último elemento es de importancia, el neosocialismo debe construir un mecanismo de contrapeso democrático que evite desequilibrios $y$ abusos de poder de ciertos grupos sociales 0 individuos. 
Una aproximación con cierto rigor científico sobre la construcción y establecimiento de una corriente neosocialista proviene de los trabajos de Dieterich (2007); Lebowitz (2007) y Mészáros (2006) los cuales aportan constructos no sólo desde la experiencia venezolana, sino además desde un análisis de las experiencias pasadas, pasando por nuevos hallazgos sobre el pensamiento de Marx y el análisis critico del modelo de desarrollo capitalista.

Los trabajos de Dieterich (2007) y Mészáros (2006) hacen aportes significativos para la construcción de un neosocialismo desde la perspectiva de realizar cambios estructurales microterritoriales y extraterritoriales, además de la necesidad de realizar transformaciones sociopolíticas que coadyuven los cambios estructurales realizados. Por otra parte, Lebowitz (2007) resalta la importancia estratégica que tiene un sistema social si se enfatiza en el desarrollo de las capacidades humanas de cada de uno de sus individuos con la finalidad de que puedan transformase a si mismo y en esa medida transformar su entorno.

La realización del neosocialismo se dará en tres etapas: i) la fase final es la sociedad sin economía de mercado (en el sentido capitalista), sin Estado y sin cultura excluyente, de este horizonte estratégico se derivan contenidos, objetivos y formas de lucha de la segunda y primera etapa; ii) la fase intermedia será un tiempo de coexistencia de elementos heredados de la sociedad capitalista y de elementos de la nueva sociedad neosocialista que servirá para la armonización gradual entre los niveles de desarrollo tecnológico, educativo, económico, político, cultural, militar, etc., de los Estados del primer mundo y de los Estados neocoloniales; porque es obvio que las disparidades en estos sectores que ha producido el capitalismo durante los últimos doscientos años, no permitirán la convivencia pacifica y democrática dentro de la sociedad global y iii) la fase inicial de superación del capitalismo global es el tiempo que estamos viviendo; esta fase se inició, en lo político, con el renacimiento del pensamiento critico en los años 90’s y se caracteriza actualmente por el proceso de constitución de la programática de la sociedad poscapitalista (Dieterich, 2007).

La genesis de un nuevo modelo de sociedad surge por considerar necesariamente los cambios que actualmente ocurren en Venezuela, englobados en la transferencia del poder a los gobernados (Albornoz y Jiménez, 2007). El gobierno del presidente Hugo Chávez Frias ha articulado un plan de desarrollo nacional (MPD, 2004; MNCI, 2007) desde una perspectiva de aprendizaje institucional ${ }^{6}$ que permite darle viabilidad a un nuevo modelo de desarrollo con un fuerte componente social. Es pertinente aclarar que las instituciones no nacen inmediamente, ellas son construcciones sociohistóricas que a lo largo de su implementación (origen, ajuste y estabilización), los sectores sociales erigen expresamente. Villegas (2007) destaca en su análisis algunos elementos que sustentan el nuevo modelo de desarrollo venezolano en el marco de un nuevo socialismo. Por una parte, la construcción de un proyecto original caracterizado por el despliegue de ideas democráticas y pacificas y la reivindicación e incorpora- 
ción de las sociedades indígenas asentadas en el territorio venezolano. Así, como la participación de las masas en función de la construcción de un partido único (PSUV). Sin embargo, Cejas (2007) señala que estos elementos no son suficientes y destaca la pertinencia de mirar hacia otras experiencias (caso chino) como un experimento susceptible de ser perfeccionado.

El modelo de desarrollo venezolano se inscribe en un proceso de cambio que inicio en el año 1999 con cambios jurídicos y estructurales en casi todos los sectores sociales y una política exterior orientada a informar, cooperar y consolidar la integración latinoamericana y desarrollando una agenda con temas prioritarios para la región (como son las áreas energética, social, política, económica, militar, educativa, tecnológica y cultural). En este sentido, siguiendo al MINCI (2007) se propusieron Las Líneas Generales del Plan de Desarrollo Económico y Social de la Nación 20072013. Estas líneas de acción contemplan:

\section{Nueva ética socialista}

Esta línea de acción contempla el rescate de la ética y la moral como elementos esenciales para articular el neosocialismo, valores que sentaran las bases de una corriente humanista donde prevalezca la equidad y la justicia social. Con la finalidad de que cada ciudadano alcance la suprema felicidad y se den los primeros pasos en la construcción del hombre nuevo. Esta premisa pasa por considerar: i) los derechos humanos de la primera generación: derechos civiles y políticos, derechos de la libertad, derecho a la vida, a la libertad de conciencia, derecho a pensar y expresarse libremente; ii) los derechos humanos de la segunda generación: derechos económicos, sociales y culturales; y iii) los derechos humanos de la tercera generación: derechos de nacer y vivir en un ambiente sano, no contaminado y el derecho a nacer y vivir en una sociedad en paz. Las estrategias diseñadas para alcanzar este objetivo son: i) transformar la sociedad material y espiritualmente; ii) desarrollar la conciencia revolucionaria; y iii) superar la ética del capital.

\section{Suprema felicidad social}

Esta línea de acción contempla la visión de largo plazo que tiene como punto de partida la construcción de un sistema socioeconómico incluyente, que contribuya a la construcción de una sociedad más humana y permita satisfacer las necesidades sociales vinculadas a los subsistemas empleo-producción-distribución de bienes y servicio. La conexión interfasica ${ }^{7}$ de estos subsistemas es propicia debido a que se están creando nuevas relaciones de producción (empresas de producción social) y redes sociales (consejos comunales), que permitirá proyectar el empoderamiento productivo de los grupos sociales, particularmente en territorios especificos. Los objetivos planteados son: i) reducir la miseria a cero y acelerar la disminución de la pobreza; ii) transformar las relaciones sociales de producción construyendo unas de tipo socialista basadas en la propiedad social; iii) fortalecer las capacidades básicas para el trabajo productivo; iv) pro- 
mover una ética, cultura y educación liberadoras y solidarias; y v) profundizar la solidaridad con los excluidos de América Latina y el Caribe. Las estrategias diseñadas para alcanzar estos objetivos son: i) superar la pobreza y atender integralmente a la población en situación de extrema pobreza y máxima exclusión social; ii) profundizar la atención integral en salud de forma universal; iii) garantizar el acceso a una vivienda digna; iv) profundizar la universalización de la educación bolivariana; v) masificar una cultura que fortalezca la identidad nacional, latinoamericana y caribeña; vi) garantizar una seguridad social universal y solidaria y los mecanismos institucionales del mercado de trabajo; vii) garantizar la administración de la biosfera para producir beneficios sustentables; y viii) fomentar la participación organizada del pueblo en la planificación de la producción y la socialización equitativa de los excedentes.

\section{Democracia protagónica revolucionaria}

Esta línea de acción fomenta la democracia protagónica y participativa como expresión genuina y auténtica de la verdadera democracia, considera los espacios públicos y privados complementarios y no separados y contrapuestos como en la ideología liberal. Proyecta la construcción de una entidad individual y grupal sociopolítica altamente crítica que permita actuar como contrapeso a los desequilibrios institucionales del Estado. Los objetivos planteados son: i) alcanzar irrevocablemente la democracia protagónica revolucionaria, en la cual, la mayoría soberana personifique el proceso sustantivo de toma de decisiones; ii) construir la base sociopolítica del neosocialismo; iii) formar una nueva cultura política basada en la conciencia solidaria del ciudadano, de sus derechos y responsabilidades, iv) construir un sector público al servicio del ciudadano que conduzca a la transformación de la sociedad; v) ampliar los espacios de participación ciudadana en la gestión pública; vi) fortalecer la práctica de la información veraz y oportuna por parte de los medios de comunicación masivo; vii) fomentar que los medios de comunicación masivos formen parte de la promoción y defensa de la soberanía nacional; y viii) consolidar al sistema de comunicación nacional como instrumento para el fortalecimiento de la democracia protagónica revolucionaria y la formación. Las estrategias diseñadas para alcanzar estos objetivos son: i) fomentar la capacidad de toma de decisiones de la población; ii) convertir los espacios escolares, en espacios para la enseñanza y la práctica; iii) desarrollar una red eficiente de vías de información y de educación no formal hacia el pueblo; iv) construir la estructura institucional necesaria para el desarrollo del poder; v) garantizar la participación protagónica de la población en la administración pública nacional; vi) elevar los niveles de equidad, eficacia, eficiencia y calidad de la acción pública; vii) construir una nueva ética del servidor público; viii) combatir la corrupción de manera sistemática en todas sus manifestaciones; ix) fomentar la utilización de los medios de comunicación como instrumento de formación; x) promover el equilibrio entre los deberes y derechos informativos y los comunicacionales de los ciudadanos y las ciudadanas; xi) universalizar el acceso a los diferentes tipos de comunicación; y xii) promover la soberanía comunicacional. 


\section{Modelo productivo socialista}

En esta línea de acción el planteamiento principal es el combate a la pobreza vinculado al desarrollo rural, por lo tanto propone políticas diferenciadas que permite atender las condiciones de desigualdad que imperan en el campo y que las unidades domésticas campesinas ${ }^{8}$ sean los sujetos de las políticas, pasar de la producción agrícola a los encadenamientos de ésta con la agroindustria y reconstruir las instituciones como formas de mediación entre los distintos actores sociales. Los objetivos planteados son: i) desarrollar el nuevo modelo productivo endógeno como base económica del neosocialismo y alcanzar un crecimiento sostenido; ii) incrementar la soberanía alimentaría y consolidar la seguridad alimentaría; iii) fomentar la ciencia y la tecnología al servicio del desarrollo nacional y reducir diferencias en el acceso al conocimiento; y iv) desarrollar la industria básica no energética, la manufactura y los servicios básicos. Las estrategias diseñadas para alcanzar estos objetivos son: i) mejorar sustancialmente la distribución de la riqueza y el ingreso; ii) expandir la economía social cambiando el modelo de apropiación y distribución de excedentes; iii) fortalecer los sectores nacionales de manufactura y otros servicios; iv) asegurar una participación eficiente del Estado en la economía; v) consolidar el carácter endógeno de la economía; vi) incrementar la participación de los productores y concertar la acción del Estado para la agricultura; vii) consolidar la revolución agraria y eliminar el latifundio; viii) mejorar y ampliar el marco de acción, los servicios y la dotación para la producción agrícola; ix) rescatar y ampliar la infraestructura para el medio rural y la producción; x) incrementar la producción nacional de ciencia, tecnología e innovación hacia necesidades y potencialidades del país; xi) rediseñar y estructurar el Sistema Nacional de Ciencia, Tecnología e Innovación (SNCTI); xii) incrementar la cultura científica; y xiii) mejorar el apoyo institucional para la ciencia, la tecnología y la innovación.

\section{Nueva geopolítica nacional}

En Venezuela las actividades económicas han sido históricamente inducidas desde los países hegemónicos del sistema mundial, estableciendo un modelo económico altamente dependiente de intereses de poder favorables a la desnacionalización y a la escasa diversificación productiva. Por ello el patrón de organización socioterritorial se ha dirigido hacia la costa en la etapa agroexportadora y luego hacia el subsistema central nortecostero en la Venezuela petrolera, rasgo típico de una economía de puertos de carácter extractiva, que privilegia la concentración en este subsistema. En este sentido, la dinámica urbano-regional del territorio venezolano ha seguido desde mediados del siglo pasado, un patrón de ocupación concentrado, desequilibrado y polarizado, cuya expresión actual muestra fuertes desigualdades interregionales, generando importantes problemas sociales y ambientales.

En este contexto, esta línea de acción contempla la construcción y organización espacial de un nuevo modelo socioproductivo endógeno, pro- 
picio para la consolidación de las nuevas relaciones de producción y redes sociales. La consolidación de los espacios micro y macroterritoriales teniendo como eje articulador a sus pobladores a través del desarrollo de sus capacidades naturales dará paso a las transformaciones sociales necesarias para que su patrimonio sea bien administrado y trasmitido por herencia, permitiendo a su vez sentar las bases de un desarrollo sustentable. Con referencia a la temática, el estudio de Linck et al. (2006) destaca la importancia de la apropiación colectiva remitiendo a la noción de patrimonialización ${ }^{9}$.

La proyección de una novísima estructura socioterritorial profundizará la integración nacional y permitirá aprovechar sus potencialidades y fortalezas, en este sentido, se han identificado cinco (5) ejes: i) el eje Norte-Costero; ii) el eje Orinoco-Apure; iii) el eje Occidental; iv) el eje Oriental; y v) el eje Norte-Llanero que operara como articulador. La dinámica socioeconómica que se genere permitirá la construcción de distintos corredores de infraestructura (modernización y construcción de vías de comunicación (terrestre, aéreo, fluvial y ferroviario), el acceso energético en sus distintas modalidades y las telecomunicaciones). Estas transformaciones socioestructurales favorecerán la integración geoestratégica con América Latina y el Caribe (Figura 1). La lógica productiva propuesta si bien ha sido documentada y relacionada a la dinámica capitalista (Cortez, 2004), es un elemento novedoso desde la perspectiva neosocialista que permite su establecimiento y replicación en una dialéctica no conflictiva con el modelo de desarrollo capitalista durante su fase de desarrollo.

\section{Figura 1. Modelo socioterritorial propuesto.}

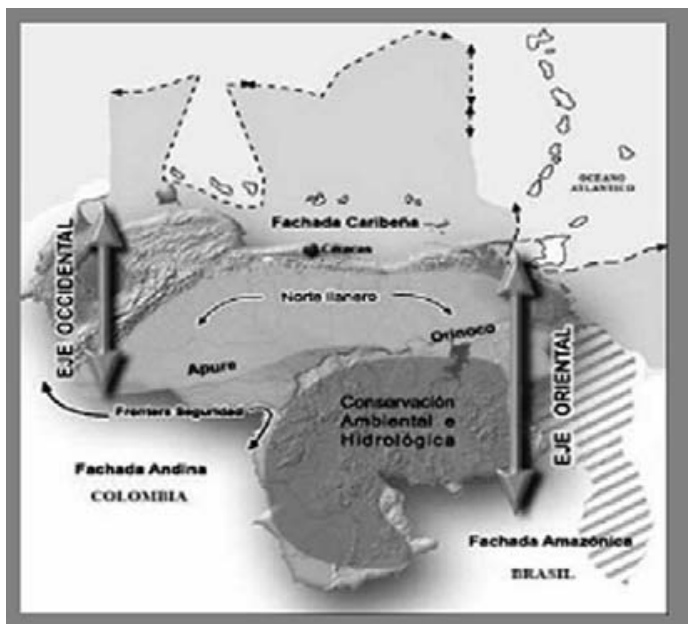

Fuente: Líneas Generales del Plan de Desarrollo Económico y Social de la Nación 2007-2013 (MINCI, 2007). 
Los objetivos planteados, enmarcados en un proyecto más amplio (Proyecto Nacional Simón Bolívar 2007-2021), son: i) profundizar la cohesión y la equidad socio-territorial; ii) desconcentrar actividades y población; iii) aprovechar las fortalezas regionales creando sinergias entre ellas; iv) hacer posible una ciudad incluyente con calidad de vida; v) proteger espacios para conservar el agua y la biodiversidad; vi) elevar los niveles de conciencia ambiental en la población; vii) preservar los equilibrios de los ecosistemas ricos en biodiversidad; viii) alcanzar un modelo de producción y acumulación ambientalmente sustentable; ix) disminuir el impacto ambiental de la intervención humana; y x) recuperar los suelos y cuerpos de aguas degradados. Las estrategias diseñadas para alcanzar estos objetivos son: i) mejorar la infraestructura para la integración con América Latina y el Caribe; ii) integrar y desarrollar el territorio nacional a través de ejes y regiones; iii) ordenar el territorio asegurando la base de sustentación ecológica; iv) mejorar el habitat de los principales centros urbanos; v) reforzar el sistema de ciudades intermedias; vi) conservar y preservar ambientes naturales; vii) ajustar el metabolismo urbano disminuyendo la carga sobre el ambiente; y viii) generar alternativas ante la explotación de los recursos no renovables.

\section{Venezuela: potencia energética mundial}

Debido al creciente aumento de la demanda de energía fósil en el mundo y la magnitud de las reservas de esas materias primas, el petróleo continuara teniendo una influencia significativa en el futuro de Venezuela. El petróleo será decisivo, más allá del horizonte del programa para la captación de recursos del exterior, la generación de inversiones productivas internas, la satisfacción de las propias necesidades de energía y para el apoyo y consolidación del neosocialismo.

En este contexto, esta línea de acción contempla el fortalecimiento de Venezuela, como un país que posee una de las mayores reserva petrolera en el mundo en sus distintas modalidades (liviano, mediano y pesado). Esto le permitirá al país a mediano y largo plazo obtener los recursos necesarios para fortalecer y darle sosteniblidad al modelo de desarrollo propuesto. Por otra parte, representa un elemento esencial en la política exterior venezolana con miras a la integración latinoamericana y caribeña desde una perspectiva solidaria. Además de que consolida su posicionamiento en el escenario energético mundial. Los objetivos planteados son: i) convertir a Venezuela en una potencia regional y fortalecer la integración energética latinoamericana y caribeña; ii) acelerar la siembra del petróleo, profundizando la internalización de los hidrocarburos para fortalecer la diversificación productiva y la inclusión social; iii) asegurar que la producción y el consumo de energía contribuya a la preservación del ambiente; y iv) propiciar, un cambio radical hacia la generación térmica de energía eléctrica adicional con base en el gas y otras fuentes de energía alternativas. Las estrategias diseñadas para alcanzar estos objetivos son: i) profundizar la internalización de los hidrocarburos; ii) incrementar la producción de energía eléctrica, expandir y adaptar el sistema de transmisión y distribución; iii) propiciar el uso de fuentes de energía alternas, renovables y 
ambientalmente sostenibles; iv) promover el uso racional y eficiente de la energía; v) profundizar la política de maximización de la captación de la renta petrolera en todas las fases del proceso; vi) preservar y mejorar el ambiente y la calidad de vida de las comunidades afectadas por la utilización de hidrocarburos, como fuente de energía; vii) fortalecer la integración latinoamericana y caribeña; y viii) privilegiar la inversión en investigación y desarrollo tecnológico en materia de hidrocarburos y energía eléctrica.

\section{Nueva geopolítica internacional}

En los últimos 9 años Venezuela ha implementado una intensa política exterior, rompiendo con la pasividad histórica que caracterizo la relación de Venezuela con el mundo, en la cual el elemento fundamental fue la mediatización y subordinación a los intereses geopolíticos del imperialismo norteamericano. En la actualidad, ha recuperado su independencia y soberanía en la formulación de su agenda internacional, las nuevas circunstancias presentes determinan que Venezuela avance hacia una nueva etapa en la geopolítica mundial, fundamentada en una relación estratégica de mayor claridad en la búsqueda de objetivos de mayor liderazgo mundial.

En este contexto, esta línea de acción contempla una estrategia de conducción multipolar de la política mundial, que se aplica mediante la diversificación de las relaciones políticas, económicas y culturales, para la creación de nuevos bloques de poder atendiendo las particularidades, de acuerdo al establecimiento de áreas de interes geoestratégicas. La creación de un mundo multipolar implica la creación de nuevos polos de poder que representen el quiebre de la hegemonía del imperialismo norteamericano, en la búsqueda de la justicia social, la solidaridad y las garantías de paz bajo la profundización del dialogo fraterno entre los pueblos, el respeto de las libertades de pensamiento, religión y la autodeterminación de los pueblos. Esta visión se fundamenta en la identificación y definición de una política de construcción y articulación de los nuevos polos de poder geopolíticos en el mundo; el afianzamiento de los intereses políticos comunes entre los países; la profundización de la amistad, confianza y solidaridad, para la cooperación y coexistencia pacifica entre los pueblos; la conformación de un nuevo mapa geopolítico en el desarrollo energético; la construcción de nuevos esquemas de cooperación económica y financiera para el apalancamiento del desarrollo integral. Por otra parte, se proyecta la conformación de áreas de interes geoestratégicas, dichas áreas se definirán de acuerdo al interes estratégico nacional, tomando en consideración las características, el nivel de las relaciones y la afinidad política existente, con la finalidad de orientar la política exterior venezolana, en función de la construcción de nuevos polos de poder.

Los objetivos planteados son: i) fortalecer la soberanía nacional acelerando la conformación del bloque geopolítico regional y de un mundo multipolar; ii) diversificar las relaciones políticas, económicas y culturales, de acuerdo con el establecimiento de áreas de interes geoestratégicas; y iii) profundizar el dialogo fraterno entre los pueblos, el respeto de las liberta- 
des de pensamiento, religión y la autodeterminación. Las estrategias diseñadas para alcanzar estos objetivos son: i) mantener relaciones soberanas ante el bloque hegemónico mundial; ii) desarrollar la integración con países de América Latina y el Caribe; iii) favorecer relaciones solidarias con otros países en desarrollo; iv) avanzar en la transformación de los sistemas multilaterales de cooperación e integración mundial, regional y local; v) construir la institucionalidad de un nuevo orden de integración financiera y el establecimiento del comercio justo; vi) profundizar el intercambio cultural y la independencia científica y tecnológica; y vii) crear un nuevo orden comunicacional internacional.

\section{Implicaciones para el re-diseño institucional}

El diseño institucional neosocialista debe tener como hilo conductor la cultura de la formación social en cuestión, es decir estas sociedades poseen instituciones informarles que se han generado en un espacio-temporal, eliminar estas instituciones es muy difícil, se debe considerar que la construcción e innovación de instituciones formarles debe considerar sus contrapartes informarles (por ejemplo, es difícil introducir la propiedad comunal o colectiva en países donde las personas sólo conciben la propiedad privada y pública). Chang (2006); North (2006) y Hodgson (2006) destacan algunos elementos claves para la compresión de las instituciones informales. Estos autores creen conveniente la creación de instituciones robustas adaptadas a las complejidades de un sistema social en permanente cambio, pero esta visión según la perspectiva de Streeten (2007) tiene una limitante, que la concepción economicista imperfecta y alienadora que tiene la sociedad actual encabezada por la academia en especial aquella de los países industrializados impide cualquier valoración fuera de los marcos de desarrollo actual.

En este contexto, es pertinente una revisión de lo que se conceptualiza como institución.

North (1990) define:

[...]...a las instituciones como un conjunto de limitaciones formales e informales, creadas por los seres humanos o surgidas espontáneamente de sus relaciones, y de mecanismos para hacer cumplir obligatoriamente sus acuerdos. Las limitaciones formales son normas escritas, como las constituciones, leyes y contratos, cuya modificación implica grados de dificultad diferentes. Dichas normas, que regulan los intercambios y definen los derechos de propiedad, crean incentivos para la acción de los individuos. Los individuos con intereses comunes se agrupan en organizaciones, con el fin de aprovechar las oportunidades creadas por las instituciones. Tales organizaciones pueden ser políticas, como la Asamblea Nacional y los partidos políticos, económicas, como las empresas y los sindicatos, sociales, como las iglesias y los clu- 
bes, y educativas, como las universidades. Las limitaciones informales son costumbres, tradiciones, convenciones y códigos de conducta culturalmente heredados.

La cultura, según la definición adoptada por North (1990), es un conjunto de conocimientos, valores y otros factores que influyen sobre la conducta, transmitidos de generación en generación por la enseñanza y la imitación. Cuando las limitaciones formales son poco claras o de difícil cumplimiento, los acuerdos suelen realizarse confiando en las limitaciones informales, o no realizarse.

Por otra parte, North (2006) señala:

[...]...que las instituciones desempeñan un papel esencial en el crecimiento económico. Son incentivos para crear una estructura productiva. El establecimiento de instituciones hace que la gente sea mucho más productiva y esto podemos observarlo en el caso asiático. En Latinoamérica existen muchas instituciones que promueven el crecimiento, pero también hay otras cuantas que lo limitan. Lo que necesitan en el continente es reestructurar las reglas del juego y crear instituciones que produzcan crecimiento. Pero ¿cuáles serían esas instituciones que promoverían el crecimiento económico? Nosotros sabemos que si se tienen establecidas unas estructuras fuertes de derechos de propiedad, sistemas legales que posibiliten las transacciones y eliminen los altos costos de obtener la información y otras instituciones, se producirá el resultado anhelado del crecimiento económico. El autor señala que el éxito económico chino se debe al papel que han desempeñado sus instituciones y la relevancia de los mecanismos de arreglos consuetudinarios, sociales y el intercambio personal son más importantes que un compendio de leyes.

\section{Para Echeverri y Moscardi (2005):}

[...]....las instituciones son la forma de cómo se concreta el acuerdo sobre lo público. Consideran que: i) las instituciones son los arreglos que incluyen dos componentes: las organizaciones y las reglas del juego; ii) entre las reglas del juego hay unas formales y otras informales que tienen el mismo peso e incidencia; iii) la ley es la formalización mayor de las reglas del juego, pero hay otras como la ética y la cultura que tienen peso e incidencia; iv) entre las organizaciones existen unas formales y otras informales y v) entre las organizaciones formales, hay unas públicas, que constituyen el Estado, y otras privadas.

Para el presente estudio, las instituciones se definen como un sistema de acuerdos regidos por un subsistema de normas formales y/o consuetudinarias que se construyen para encauzar relaciones de intercambio económico, social, político y ambiental, todo en función de la idiosincrasia o sistema cultural imperante en la formación social.+ 
Desde mi perspectiva de análisis es relevante ubicar la naturaleza del modelo institucional. En este sentido, el modelo de desarrollo neosocialista venezolano se sustenta en un desarrollo institucional si se quiere innovativo, ya que se aleja de los marcos valorativos de un modelo esencialmente capitalista, se caracteriza por tener: una democracia participativa y protagónica, un sistema judicial independiente, una burocracia profesional, un sector de empresas pública grande, un mercado de valores desarrollado, un régimen de regulación financiera que incentiva la prudencia y la estabilidad, a través de un banco central independiente. Las formas institucionales son diversas, así como sus funciones.

Por otra parte, las formas institucionales de carácter consuetudinarias animadas por nuevas relaciones de producción y un emergente tejido social están adquiriendo una importancia sin precedentes en los territorios venezolanos, a su vez que actúa como un elemento que configura dichos espacios. Es claro que las instituciones consuetudinarias surgen con la finalidad de construir el bienestar colectivo en un determinado microterritorio y deben su permanencia a un legado transhistórico ${ }^{10}$ de una formación social que no se puede dejar a un lado cuando se innova o se diseñan instituciones formarles.

El diseño institucional debe descansar entre tres (3) elementos estratégicos, estos son: i) derechos de propiedad definidos y estables; ii) sistema de justicia robusto; iii) consideración del sistema cultural imperante o normas consuetudinarias a través de instancias organizativas microterritoriales, en el caso venezolano existen los consejos comunales ${ }^{11}$.

Partiendo de los elementos anteriormente mencionados, en la construcción del diseño institucional se deben identificar los insumos y los elementos claves (Figura 2).

\section{Figura 2. Modelo analítico para el diseño institucional}

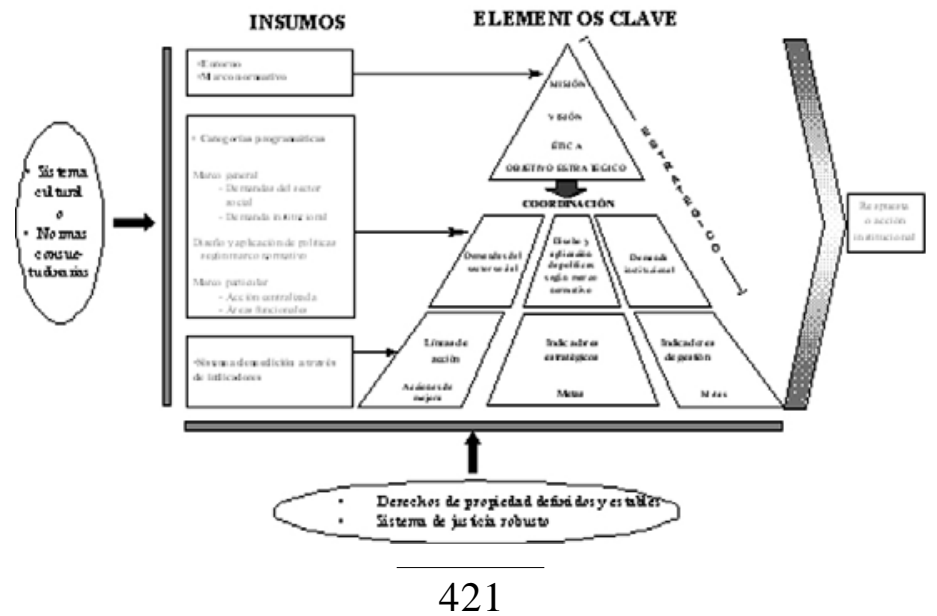


En los insumos se identifican cuatro (4) elementos en orden jerárquico: i) el entorno: referido al marco de actuación y alcance institucional; ii) el marco normativo: toda institución actúa bajo un marco normativo o ley; iii) las categorías programáticas: en éstas se ubican el marco general que representan su justificación, el diseño y aplicación de políticas públicas según el marco normativo vigente y las acciones particulares, referidas a que el marco de construcción de políticas va en función de una política nacional y su replicación debe abarcar todas las áreas funcionales y iv) finalmente, en la construcción de un sistema de medición a través de indicadores que permita evaluar y corregir en un continuum las acciones institucionales que garanticen la eficiencia y eficacia de la instancia institucional.

En los elementos claves se identifican dos (2) grandes aspectos en orden jerárquico: los elementos estratégicos que abarcan por una parte; la misión, visión, ética y objetivos estratégicos de la institución y por otra, la puesta en operación que corresponderá a las categorías programáticas. El segundo aspecto corresponde a la construcción de los indicadores y el establecimiento de las líneas de acción, así como las acciones de mejoras institucional. En la elaboración de los indicadores y metas se prevé la utilización de indicadores de estratégicos y de gestión. Estos indicadores facilitan apreciar distintos aspectos de los resultados obtenidos: i) impacto, evalúa el alcance en el cumplimiento de los objetivos; ii) cobertura, evalúa el volumen de atención de la población objetivo; iii) eficiencia, evalúa el aprovechamiento de los recursos; y iv) calidad, evalúa la pertinencia en que recibe el usuario el servicio y su satisfacción respecto a su expectativa.

Indicadores estratégicos: Son los parámetros de medición del cumplimiento de los objetivos estratégicos. Se caracterizan por: i) dirigidos al cuerpo directivo alto y medio; ii) están referidos al logro de los objetivos estratégicos; y iii) deben apegarse al alcance que tiene el quehacer del grupo de trabajo.

Indicadores de Gestión: Son los parámetros de medición del cumplimiento de los objetivos o propósitos de cada proceso clave con los que opera la institución. Se caracterizan por: i) dirigidos al cuerpo directivo bajo; ii) al establecer indicadores de gestión es importante que se tomen como referencia los objetivos y metas estratégicas a fin de lograr su congruencia y complementariedad; y iii) su definición parte del propósito u objetivo de cada proceso u operación clave.

En la construcción de indicadores deben considerarse: i) definir que variables conforman la formula para la obtención del indicador, el cual nos servirá de referencia para el establecimiento de la meta; ii) determinar para cada elemento crítico, la mejor manera de medir su cumplimiento; y iii) verificar que se hayan contemplado implícita o explícitamente todas las dimensiones. 
Con referencia a las metas, estas determinan la magnitud y temporalidad de los compromisos adquiridos por los grupos de trabajo con relación a los objetivos planteados; se debe hacer un análisis del contexto y situación real de la institución para la determinación de dichas metas, las cuales deben ser retadoras y alcanzables; se deben considerar diferentes escenarios (optimista, neutral, pesimista) y en función de ellos fijar las metas; es necesario determinar los factores internos y externos que tendrán mayor incidencia en el logro de las mismas y se debe establecer una meta por cada indicador.

\section{Consideración final}

Mészáros (2006) menciona:

[...]....en su obra que un orden social jamás perece antes de que todas las fuerzas productivas para las cuales él es ampliamente suficiente se hayan desarrollado dentro de su marco, tal verdad tiene implicaciones de largo alcance para las maneras en que una formación social en particular puede ser reemplazada por otra. Porque en ese respecto importa bastante el que una crisis conduzca al fracaso total y el derrumbamiento del orden social en cuestión -en cuyo caso las fuerzas productivas obviamente ya no se pueden seguir desarrollando dentro de sus confines- o bien, bajo el impacto de una crisis grave, se introduzcan nuevas modalidades de funcionamiento a fin de evitar ese fracaso. No obstante, una vez que se introducen tales cambios, se convierten en partes más o menos conscientemente adoptadas del nuevo conjunto de relaciones hibridas, redefiniendo así radicalmente los términos en que se puede concebir una subsiguiente crisis fundamental (es decir, no simplemente "periódica"). Esto se debe a que los ajustes híbridos han ampliado significativamente las potencialidades para un desarrollo continuado de las fuerzas productivas dentro del marco establecido, imponiendo así la necesidad de un reajuste profundo también en las estrategias del adversario.

Este análisis es pertinente en el marco de la dinámica transformadora que llevan actualmente las formaciones sociales de Ecuador, Bolivia y Venezuela respaldadas por cambios novísimos en sus sistemas jurídicos cónsonos con las bases iniciales de dicha transformación social. Estos elementos son relevantes porque demuestran que las complejidades de un sistema social en el marco de un modelo de desarrollo -sean económicas o sociales- son subsumidas y reinterpretadas por los grupos sociales más vulnerables o excluidos que casi siempre son la mayoría para mantener o construir estrategias de reproducción.

En este sentido, no hay duda de que la base socialista de una formación social no va depender de los gobiernos que la promuevan sino de los grupos sociales que la adopten para si, como una estrategia 
global que genere bienestar en sus distintas modalidades y en esa medida puede amplificarse extraterritorialmente, aludiendo al escenario latinoamericano.

\section{Conclusiones}

El modelo de desarrollo capitalista como instancia de control social ha demostrado ser ineficaz y alienador al menos en América Latina. Su actual crisis debido a la dinámica de cambios de naturaleza multisectorial (e.g. político, económico, social y ambiental) ha promovido transformaciones en las formaciones sociales latinoamericanas, en particular las ubicadas en Bolivia, Ecuador, Paraguay y Venezuela. Ante esta situación se ha propuesto el modelo de desarrollo neosocialista como una alternativa viable y que actualmente se encuentra en una etapa de madurez o formación teórica-metodologica y en la cual Venezuela la viene ensayando desde hace 9 años con aciertos y desaciertos. Esta alternativa se perfila como una opción distinta al poscapitalismo y al socialismo tradicional, pero considera elementos estratégicos que han definido su posición en una determinada formación social en la historia; en el primero, debe considerarse la importancia de definir y establecer solidamente los derechos de propiedad y el establecimiento de un sistema de justicia robusto. En el segundo, mirar la experiencia del pasado es fundamental para no repetir errores, es el caso del modelo de desarrollo socialista de la exUnión Soviética y sus distintas mutaciones a lo largo de su historia, por otra parte, no se puede proyectar un modelo de desarrollo con un fuerte componente social si antes no se considera y se interpreta de manera adecuada la teoría marxista.

El análisis del modelo de desarrollo neosocialista que actualmente se gesta en Venezuela se extiende a todos los sectores, su carácter multidimensional, en especial su fuerte integración social le proporcionan cualidades que en términos espacio-temporalidad le darán solidez y perpetuidad. Sin embargo, aun existen elementos perturbadores en dicho sistema como son la corrupción gubernamental y los excesos de poder microterritorial de individuos o grupos familiares y que hace necesario que se diseñen mecanismo para su control. En este sentido, el diseño de instituciones adaptado ha estas realidades es propicio, no sólo como mecanismos de contención y control, sino como entidades que promuevan el bienestar y crecimientos en un determinado sistema social.

Se construyó un modelo para el diseño de instituciones bajo un marco valorativo neosocialista, con el fin de darles respuestas a la dinámicas de cambios sociales en los territorios venezolanos, ya que actualmente a 9 años de experimentar cambios en el modelo de desarrollo capitalista, gran parte de sus socioestructuras siguen funcionando.

A partir de este estudio, podemos señalar que el diseño institucional 
cobra una importancia estratégica, las transformaciones sociales no sólo están ocurriendo en Venezuela, sino que se están extendiendo al resto de América Latina, bajo esta perspectiva es relevante construir un instrumentar teórico-metodológico que permita sustentar el modelo de desarrollo en ascenso bajo un marco valorativo neosocialismo, así como su replicación. Sin embargo, su permanencia estará en función de la satisfacción de las distintas formaciones sociales. 


\section{Notas}

${ }^{1}$ El concepto de estrategias de reproducción da cuenta de conjunto de acciones o prácticas que despliegan las unidades familiares para garantizar su supervivencia, ya sea bajo relaciones mercantiles o no mercantiles, caracterizada por el espacio local en que están insertas. Para profundizar vease (Margulis, 1980; Jáuregui, 1982).

${ }^{2}$ Las especies capitales se conforman por las distintas formas de acumulación de un bien o servicio pudiendo ser de naturaleza tangible o intangible.

${ }^{3}$ Es la manera por saber cómo y hasta qué punto podría ser posible pensar de manera diferente, en lugar de legitimar lo que ya se conoce (cit. por Parra, 2005).

${ }^{4} \mathrm{El}$ conocimiento local es un fenómeno que surge y se desarrolla a través de prácticas históricamente localizadas nacido de una experiencia arraigada., en contextos sociales e institucionales específicos. (Agrawal, 1995; Murdoch y Clark, 1994 cit. por Leach y Fairhead, 2002; Sundar, 2002); (Morales, 2001); (Geertz, 1994) y (Toledo, 1991). Se desarrolla en relación con ámbitos específicos del poder. Además, es recursivo, es decir, está sujeto a bucles de retroalimentación mediante los cuales un grupo aprende de otro e integra nuevas maneras de pensar ( $\mathrm{Li}, 2002)$.

${ }^{5}$ Poder que ejerce un individuo o familia en un microterritorio desde una perspectiva multidimensional (ámbitos político, social, económico y ambiental). Véase. a Buve (2003) y Aragort (2006) para profundizar en su origen y causas de su establecimiento.

${ }^{6}$ Una perspectiva de aprendizaje institucional esta referida a la continuidad de aplicación de un conjunto de políticas públicas.

${ }^{7}$ Se deriva de la teoría del actor social.

${ }^{8}$ La unidad doméstica campesina es una instancia analítica que tiene los atributos de una economía doméstica y mercantil. A partir de estas características puede asumir un papel económico diferenciado de acuerdo a las condiciones productivas en la que se encuentre, su funcionamiento y desempeño económico no necesariamente están determinados por la rentabilidad de sus actividades productivas (Ramírez, 1999; Galeski, 1977).

${ }^{9}$ En una perspectiva patrimonial, los recursos territoriales tienen atributos de bienes colectivos. Son bienes producidos en forma colectiva, que se relacionan íntimamente con la acción colectiva. Las capacidades técnicas y relacionales propias de un territorio, las relaciones y las prácticas en las cuales se sustenta la biodiversidad no son bienes económicos en el sentido habitual del término aunque, desde luego, están necesariamente presente en cualquier actividad productiva. El tema a despertado interés en la teoría económica, más preocupada por entender los procesos de decisiones individuales que la construcción de decisiones colectivas (Linck et al., 2006).

${ }^{10}$ El término transhistórico esta referido a la continuación relativa de los usos y costumbres que tienen una formación social, relevante para su reproducción social a lo largo de los siglos.

${ }^{11}$ Es una estructura sociopolítica microterritorial que surge como instancia de control y que se sustenta en el bien colectivo. En la norma venezolana (articulo $\mathrm{N}^{\circ} 2$ de la Ley de los 
Consejos Comunales) se definen como instancias de participación, articulación e integración entre las diversas organizaciones comunitarias, grupos sociales y los ciudadanos y ciudadanas, que permiten al pueblo organizado ejercer directamente la gestión de las políticas públicas y proyectos orientados a responder a las necesidades y aspiraciones de las comunidades en la construcción de una sociedad de equidad y justicia social (Véase la pag. web http://www.leyesvenezolanas.com/lv04.htm). 


\section{Bibliografia}

Alayón, R. (2007), La rebelión latinoamericana a la globalización neoliberal. Caracas, Ed. Instituto de Altos Estudios Diplomáticos "Pedro Gual”.

Albornoz, O. y E. Jiménez (2007), "La lógica de la academia y las contradicciones”. Fermentum. 17, 49, pp. 251-282.

Aragort, Y. (2006), "La territorialidad y la espacialidad del poder en el siglo XVIII en Venezuela”. Provincia. 16, pp. 33-45.

Ayala, J. (1996a), “Una teoría neoinstitucionalista del Estado”. En: Mercado, elección pública e instituciones. Una revisión de las teorías modernas del Estado. México, D.F, Ed. UNAM-Miguel Ángel Porrúa, pp. 315-387.

Ídem (1996b), "La teoría de Estado en la escuela de la elección pública". En: Mercado, elección pública e instituciones. Una revisión de las teorías modernas del Estado. México, D.F, Ed. UNAM-Miguel Ángel Porrúa, pp. 243-314.

Ídem (1996c), "La teoría de las fallas del mercado y la intervención del Estado en la economía”. En: Mercado, elección pública e instituciones. Una revisión de las teorías modernas del Estado. México, D.F, Ed. UNAMMiguel Ángel Porrúa, pp. 133-180.

Ayala, R. (2004), “América Latina: la reestructuración de las relaciones de dependencia”. Revista de Ciencias Sociales (Cr). 2, 103-104, pp. 115-126.

Balza, R. (2002), “Cambio institucional, ideología y desempeño económico en Venezuela: 1958 a 2002”. Temas de Coyuntura. 45, pp. 87-124.

Banko, C. (2003), "Redefiniciones del papel del Estado en América Latina”. Revista Venezolana de Economía y Ciencias Sociales. 9, 3, pp. 37-55.

Bechyn_, J. (1980), El jeannelismo y la evolución: concepto de las leyes orgánicas sin excepción. Maracay, Ed. Grafindustrial Aragua.

Boisier, S. (2001), Sociedad del conocimiento, conocimiento social y gestión territorial. Santiago de Chile. Estudios Sociales, Corporaciones de Promoción Universitaria, 107.

Bourdieu, P. (2006), Pensamiento y acción. Caracas, Ed. Monte Ávila Latinoamericana.

Buttel, F. (2005), “Algunas reflexiones sobre economía política agraria de fines del siglo XX”. Barbosa, J. y G. Neiman (Comps.) En: Acerca de la 
globalización en la agricultura (territorios, empresas y desarrollo local en América Latina). Buenos Aires. Ed. Ciccus.

Buve, R. (2003), “Caciquismo, un principio de ejercicio de poder durante varios siglos”. Relaciones. 24, 96, pp. 17-39.

Carretero, A. E. (2006), "Masas posmodernas: el retorno del exceso constreñido en la modernidad”. Revista Venezolana de Ciencias Sociales. 10, 1, pp. 11-36.

Cejas, I. (2007), “El socialismo chino: ¿una referencia histórica para la construcción del socialismo del siglo XXI en Venezuela?” Humania del Sur. 2, 2, pp. 127-144.

Chang, H. (2006), "La relación entre las instituciones y el desarrollo económico. Problemas teóricos claves”. Revista de Economía Institucional. 8, 14, pp. 125-136.

Chinchón, A. (2007), “Democracia y autoritarismo en América Latina: en busca de la década perdida (1995-2005)”. América Latina hoy. 46, pp. 173-199.

Cortez, Y. H. (2004), Descentralización productiva y territorio: Referencias teórico-conceptuales relacionadas con la economía y el ordenamiento territorial. Lima, Perú. Gama Gráfica, S.R.L.

De Angelis, M. (2003), "Reflexiones sobre alternativas, espacios comunales y comunidades o construir un mundo nuevo desde abajo”. Bajo el Volcán. 3, 6, pp. 143-167.

de la Tejera, B., García, R. y A. Santos (2006), "Desarrollo rural: reconstruyendo una utopía”. En: Ramírez Miranda, C. A; Núñez Vera, M. A; Guadarrama Zugasti, C. y A. Cruz León (Coods.). Desarrollo Rural Regional, hoy. Tomo I: el debate teórico. Cd. de México. Ed. Universidad Autónoma de Chapingo-MCDRR, pp. 45-68.

Dieterich, H. (2003), “Tres criterios para definir una economia socialista”. Utopía y Praxis Latinoamericana. 8, 20, pp. 117-132.

Ídem (2006), “La disyuntiva de cuba: capitalismo o nuevo socialismo”. Polis. 5, 13, pp. 1-6.

Ídem (2007), Hugo Chávez y el socialismo del siglo XXI. Caracas. Ed. Monte Ávila Editores Latinoamericana.

Dupas, G. (2004), “La nueva lógica global y el impasse de América Latina”. Cuadernos del CENDES. 21, 56, pp. 1-33.

Echeverri, R. y E. Moscardi (2005), Construyendo el desarrollo rural 
sustentable en los territorios de México. Bogotá. Ed. Instituto Interamericano de Cooperación para la Agricultura (IICA).

Ellner, S. (2006), “Las estrategias “desde arriba” y “desde abajo” del movimiento de Hugo Chávez”. Cuadernos del CENDES. 23, 62, pp. 73-93.

Espinoza, V. (2006), “Los nuevos agentes políticos locales: revisión estructural de la tesis de Arturo Valenzuela ¿Cómo se articulan el nivel de representación local con el nacional en la arena local y qué papel juegan el gobierno central y las políticas públicas?” Revista Mad. 14, pp. 8-18.

Fernández, A. A. (2004), “Algunas causas sociopolíticas de la crisis de representación de los sistemas de partidos: el caso de los estados de América del Sur”. Revista de Investigación y Análisis Sociopolítico y Psicosocial (POLIS). 1, 4, pp. 37-54.

Figueroa, M. E. (2006), "Políticas culturales para el desarrollo en un contexto mundializado”. Política y Cultura. 26, pp. 157-183.

Galeski, B. (1977), Sociología del campesinado. Barcelona, Ed. Península.

Geertz, C. (1994), Conocimiento local: ensayos sobre la interpretación de las culturas. Barcelona. Ed. Paidos.

Gutiérrez, P. M. (2005), “Hacia la construcción social participada de un mejor vivir”. Espiral. 11, 33, pp. 11-40.

Hodgson, G. (2007), “Institutions and Individuals: Interaction and Evolution” Organization Studie, 28, 1, pp. 95-116.

Hodgson, G. M. (2006), “Instituciones, recesiones y recuperación en las economías en transición”. Revista de Economía Institucional. 8, 15, pp. 43-68.

Houtart, F. (2001), “Es tiempo de cambiar el curso de la historia”. Utopía y Praxis Latinoamericana. 6, 13, pp. 125-129.

Jacques, M. (2003), “Modelo de participación por afección: un modelo para el desarrollo de la ciudadanía local”. Polis. 1, 5, pp. 1-23.

Jáuregui, J. (1982), “Las relaciones de parentescos”. Revista Nueva Antropología 14, pp. 12-20.

Jeannot, F. (2000), “De las fallas del mercado a las fallas de las organizaciones”. Análisis Económico. 15, 31, pp. 5-33.

Kliksberg, B. (2005), “América Latina: la región más desigual de todas”. Revista de Ciencias Sociales (RSC). 11, 3, pp. 411-421. 
Leach, M y J. Fairhead. (2002), “Modo de Contestación: la “ciencia ciudadana” y los “conocimientos indígenas” en África occidental y el Caribe”. Revista Internacional de Ciencias Sociales. 173, pp. 18-35.

Leal, N. (2006), “Ciudadanía activa: la construcción del nuevo sujeto indígena”. Opción. 22, 49, pp. 9-24.

Lebowitz, M. (2006), Más allá de El Capital: la economía política de la clase obrera en Marx. Caracas. Ed. Monte Ávila Editores Latinoamericana.

Ídem (2007), El socialismo no cae del cielo: un nuevo comienzo. Caracas.Ed. Monte Ávila Editores Latinoamericana. Disponible en: http:/ /www.minci.gob.ve/ doc/socialismo_cielo_folleto_web.pdf.

Li, T. M. (2002), “La limpieza étnica, los conocimientos recursivos y los dilemas del sedentarismo”. Revista Internacional de Ciencias Sociales. 173, pp. 94-107.

Linck, T. (s/f), “Apuntes para un enfoque territorial, agricultura campesina y sistema-terruño”. En: Los sistemas de producción en el espacio, la historia y la sociedad. México, D. F., CIDE-ORSTOM-México. pp, 1-4.

Linck, T; Barragán, E. y F. Casabianca. (2006), “De la propiedad intelectual a la calificación de los territorios: lo que cuentan los quesos tradicionales”. Agroalimentaria. 22, pp. 99-109.

Long, N. (1996), “Globalización y localización: nuevos retos para la investigación rural”. Grammont, H (Cood.). En: La sociedad rural mexicana frente al nuevo milenio. Vol. I. México D.F., Ed. Plaza y Valdés.

Ídem (1998), “Cambio rural, neoliberalismo y mercantilización: el valor social desde una perspectiva centrada en el actor”. Zendejas, S y P. de Vries (Eds). En: Las disputas por el México rural. Vol. I. Actores y campos sociales. Michoacán, Ed. Colegio de Michoacán, pp. 45-71.

Long, N. (2007), Sociologia del desarrollo: una perspectiva centrada en el actor, México, D. F., Ed. Colegio de San Luis-CIESAS, p. 499.

Lugo, D. R. (2006), “Aproximación a la construcción de un concepto de etnocompetitividad y algunos aportes metodológicos para su aplicación”. Ramírez Miranda, C. A; Núñez Vera, M. A; Guadarrama Zugasti, C. y A. Cruz León (Coods.). En: Desarrollo Rural Regional, hoy. Tomo I: el debate teórico. Cd. de México, Ed. Universidad Autónoma de ChapingoMCDRR, pp. 195-204.

Lugo, D., Ramírez, J., Navarro, H. y N. Estrella. (2006), Etnocompetitividad: elemento de las estrategias de reproducción de los grupos sociales. Caracas, Colegio de Postgraduados.Comala.com. 
Margulis, M. (1980), "Reproducción social de la vida cotidiana y reproducción del capital”. Revista Nueva Antropología 13-14, pp. 7-12.

Mészáros, I. (2006), Más allá del capital: hacia una teoría de la transición. Caracas, Ed. Vadell Hermanos Editores.

Meyer, L. (2005), “Resistencia y esperanza: el futuro de la comunalidad en un mundo globalizado”. Rev. Identidades. 15, pp. 4-15.

MINCI (Ministerio de Comunicación e Información) (2007), Líneas generales del Plan de Desarrollo Económico y Social de la Nación 2007-2013. Documento de Trabajo. Caracas. 68 p. Disponible en: http:// archivos.minci.gob.ve/doc/lineas_generales_de_la_nacion.pdf

Monedero, J. C. (2007), “En donde está el peligro...la crisis de la representación y la construcción de alternativas en América Latina”. Cuadernos del CENDES. 24, 64, pp. 23-58.

Morales, H. (2001), “La validación del conocimiento tradicional”. Revista Ecofronteras. 13, p. 16.

Moreano, H. y C. Donoso. (2006), “Populismo y neopopulismo en Ecuador”. Revista Opera. 6, 6, pp. 117-140.

MPD (Ministerio de Planificación y Desarrollo). (2004), Hacia una Venezuela productiva. Documento de Trabajo. Caracas. 32 p. Disponible en: http://www.mpd.gob.ve

North, D. (1990), Institutions, Institutional Change and Economic Performance. Cambridge, Cambridge University Press.

Idem (2006), "Entrevista a Douglas North: lo que se necesita en América Latina es crear instituciones que produzcan crecimiento”. Perspectiva. 5, pp. 31-34. Disponible en: http://www.icpcolombia.org

Ortiz, E. y Y. Rincón. (2006), “La política social en América Latina en el marco del desarrollo humano y la democracia”. Revista Venezolana de Ciencias Sociales. 10, 1, pp. 161-175.

Parker, D. (2006), “¿De qué democracia estamos hablando?” Revista Venezolana de Economía y Ciencias Sociales. 12, 1, pp. 89-99.

Parra, M. A. (2005), "La construcción de los movimientos sociales como sujeto de estudios en América Latina”. Athenea Digital. 8, pp. 72-94.

Pereira, V. (2000), “La visión económica de los venezolanos: un análisis de coherencia ideológica”. Revista de Ciencias Sociales. 6, 1, pp. 65-82.

Quijano, A. (2004), “El laberinto de América Latina: ¿hay otras salidas?” 
Revista Venezolana de Economía y Ciencias Sociales. 10, 1, pp. 75-97.

Ramírez, J. (1999), Ajuste estructural y estrategias campesinas de reproducción en el Valle de Puebla. Tesis Doctoral. Puebla, Colegio de Postgraduados.

Rauber, I. (2006), América Latina. Poder y Socialismo en el siglo XXI. Caracas, Ed. Vadell Hermanos Editores.

Rentaría, M. A. (2003), "Identidad y cultura de los pueblos indios, en el México actual”. Michoacán, Ponencia del Congreso del AMER: el cambio en la sociedad rural mexicana.

Rivas, J. A. (2003), “El neoinstitucionalismo y la revalorización de las instituciones”. Reflexión Política. 9, pp. 36-46.

Romero, J. E. (2002), “Hugo Chávez: construcción hegemónica del poder y desplazamiento de los actores tradicionales en Venezuela (1998-2000)”. Utopía y Praxis Latinoamericana. 7, 17, pp. 73-86.

Rousseau, J.J. (1970), Discurso sobre el origen y los fundamentos de la desigualdad entre los hombres. Barcelona, Ed. Ediciones Península.

Rubio, B. (2006), “El panorama teórico rural contemporáneo”. Ramírez Miranda, C. A; Núñez Vera, M. A; Guadarrama Zugasti, C. y A. Cruz León (Coods.). En: Desarrollo Rural Regional, hoy. Tomo I: el debate teórico. Cd. de México, Ed. Universidad Autónoma de Chapingo-MCDRR, pp. 69-92.

Sánchez, I. (2004), “El capitalismo imperio y la teoría critica”. Nómadas. 9, pp. 1-36.

Schejtman, A. y J. Berdagué. (2003), Desarrollo Territorio Rural. Documento de Trabajo. Santiago de Chile, RIMISP.

Shaikh, N. (2006), "Desarrollo como libertad. Entrevista con Amartya Sen”. Cuadernos del CENDES. 23, 63, pp. 123-137.

Streeten, P. (2007), “¿Qué está mal en la economía contemporánea?” Revista de Economía Institucional. 9, 16, pp. 35-62.

Sundar, N. (2002), "Indigenizar, nacionalizar y espiritualizar-¿un programa para la educación?” Revista Internacional de Ciencias Sociales. 173, pp. 49-61.

Toledo, V. (1991), El juego de la supervivencia. Un manual para la investigación etnoecologica en Latinoamérica. México, D.F., CLADES.

Torrico, M. (2006), “¿Qué ocurrió realmente en Bolivia?”, Perfiles Latinoamericanos. 28, pp. 231-261. 
Uharte, L. M. (2005), "Política social y democracia un "nuevo” paradigma”. Revista Venezolana de Economía y Ciencias Sociales. 11, 3, pp. 93-114.

Vargas, J. G. (2003), “Teoría de la acción colectiva, sociedad civil y los nuevos movimientos sociales en las nuevas formas de gobernabilidad en Latinoamérica”. Espacio Abierto. 12, 4, pp. 523-537.

Vera, M. A. (2006), “Cogestión de empresas y transformación del sistema económico en Venezuela: algunas reflexiones”. Gaceta Laboral. 12, 2, pp. 171-186.

Villegas, S. (2007), “Algunos aportes para el debate sobre la construcción del socialismo en Venezuela”. Humania del Sur. 2, 2, pp. 39-48.

Vite, M. A. (2007), “La ideología neoliberal y la globalización económica”. El Cotidiano. 22, 142, pp. 84-91.

Recibido: 6.11.2009

Aceptado: 10.06.2010 